\title{
EDITORIAL
}

\section{Martina Šochmanová}

President, Czech Association of Nurses

Deputy Director for Nursing Care Institute for Clinical and Experimental Medicine in Prague, Czech Republic

\section{Dear readers,}

the first half of a rather exceptional year came to a close. The World Health Organization designated 2020 as the International Year of the Nurse and the Midwife.

When making that decision, the WHO hardly expected its relevance with regard to the pandemic that we have experienced.

All health workers, particularly nurses, became unintentional heroes of 2020. Healthcare professions including nursing and midwifery have received due credit throughout the world.

It was nurses who have shown that their role in the healthcare system is irreplaceable and that multidisciplinary cooperation is crucial. The general public have realized that without health professionals, no economy and no country would function. Health workers did not give up, showing their preparedness to help others even though their own health and lives were at risk. Dear colleagues, you deserve our respect for that.

The pandemic seems to be under control, as we all believe. Finally, the time has come for us to sit back and relax, for example, by reading a new issue of the Journal which brings you information and knowledge that you may find relevant and attractive.

Dear readers, let me wish you a pleasant and enriching time while reading this issue. Hopefully, it will be of help and guidance not only in arduous situations.

Once again, many thanks for your work.

PhDr. Martina Šochmanová, MBA e-mail: martina.sochmanova@ikem.cz 